\title{
A ESPECIALIZAÇÃO DAS DELEGACIAS DE POLÍCIA NOCOMBATE AOS CRIMES AMBIENTAIS COMO MEIO DE PROTEÇÃO DO MEIO AMBIENTE
}

\section{SPECIALIZATION OF POLICE STATIONS ENVIRONMENTAL CRIMES AS ENVIRONMENTAL PROTECTION MEANS}

\author{
Juliana Buck Gianini \\ Vivian Valverde Corominas
}

\section{RESUMO}

O fortalecimento das instituições governamentais voltadas ao enfrentamento dos crimes ambientais, por meio da adoção de arrojadas estratégias de gestão pública é indispensável para a promoção do desenvolvimento sustentável e a prevenção de crimes desta natureza, uma vez que o uso dessas técnicas acarreta em melhores resultados e serviços prestados à população. Esta pesquisa objetiva destacar a importância da criação de Delegacias de Polícia Especializadas no combate aos crimes contra o Meio Ambiente (Lei Federal no 9. 605/1998), no âmbito do Estado de São Paulo, com atribuição no exercício das atividades de polícia judiciária, destacando ainda os órgãos institucionais incumbidos da polícia administrativa e preventiva especializada. Terá relevância a discussão sobre a exclusividade de atuação da Polícia Civil e Polícia Militar Ambiental, desde o registro à apuração das infrações penais contra o meio ambiente, visando a obtenção de maior eficiência, eficácia e efetividade no desenvolvimento de suas ações preventivas e repressivas, valendo-se, para tanto, do enfoque na gestão pública especializada, imprescindível para o alcance dos objetivos da Segurança Pública dos Estados voltados a proteção ambiental.

Palavras-Chave: Crimes Ambientais. Órgãos Institucionais de Proteção e Repressão aos crimes ambientais. Delegacias de Polícia Especializadas. Efetividade de Proteção ao Meio de Ambiente.

\begin{abstract}
The strengthening of government institutions which struggle against environment crimes by adopting innovative strategies in public administration is mandatory for promoting sustainable development and prevention of such crimes. Those practices foster better results in public services offered to the population. This paper intends to highlight the installation of Special

\footnotetext{
Professora, Delegada de Polícia do Estado de São Paulo, Especialista em Processo Penal, Mestranda em Direito Ambiental pela Universidade Católica de Santos. Bolsista Instituição.

${ }^{2}$ Assessora Institucional da Prefeitura de Guarujá, Procuradora Municipal licenciada, advogada, mestranda em Direito Ambiental pela Universidade Católica de Santos (UNISANTOS), pós-graduada em Direito Público e em Direito Notarial e Registral Imobiliário, membro do Grupo de Pesquisa sobre Direito Ambiental das Cidades (UNISANTOS) e patrocinada pela CAPES/PROSUP.
} 
Police Stations devoted to investigate crimes against the environment (Federal Law 9605/1998) within Sao Paulo State borders. Those Special Police Stations are tasked to execute judiciary police procedures meanwhile other agencies are in charge of administrative and specialized prevention enforcement. This work features an important discussion regarding exclusive prerogatives held by the Civil Police and the Environment Military Police related to recording and prosecution of penal violations against the environment. The text intends to propose greater efficiency and effectiveness during the execution of either preventive or repressive police measures. This work emphasizes setting specialized public administration focused on environment protection in order to reach all goals for public safety which were established by Federal Law.

Keywords: Crimes against environment. Agencies for protection and prosecution of environment crimes. Special Police Stations. Effectiveness on environment protection.

\section{INTRODUÇÃO}

Diariamente são noticiados, pelos diversos veículos de comunicação social (imprensa escrita, falada,eletrônicaetelevisiva), gravese recorrentes crimes ambientais, comprometedores do equilíbrio ecológico e social de todaa comunidade local envolvida.

Este estudo tem por objetivo apresentar e discutir os motivos porque, muitas dessas infraçõespenais nãosãodevidamente apuradas, principalmente devidoàreduzidacapacidade de fiscalização e, por conseguinte,de responsabilização das pessoas físicas e jurídicas quecometemessas modalidades delituosas, produtos da ineficiência e da ineficácia dos órgãos de defesa e proteção do meio ambiente.

Verificar-se-á que as infrações penaisambientais impossibilitam a efetivaçãodo desenvolvimento local sustentável, visto que impactam toda a sociedade, causando danos, muitas vezes, irreparáveis aos recursos ecossistêmicos deste planeta, colocando em risco a “obtenção e a manutenção da vida com qualidade e dignidade” (CRUZ, 2008, p.32).

Será abordada a questão da intervenção direta, planejada e integrada do Poder Público, através dos vários órgãos operadores do Direito, a saber: o Ministério Público, Polícia Militar Ambiental e Polícia Civil, com foco para o Estado de São Paulo. Sendo discutida ainda a relevância da recente criação por meio do Decreto Estadual n 59.374 de 2.013, da Divisão de Investigações sobre Infrações de Maus Tratos a Animais e demais Infrações contra o Meio Ambiente, pelaSecretaria de Segurança Públicado Estado de São Paulo. 
Será discutida a necessária e adequada efetivação de políticas públicas voltadas a preservação do meio ambiente, sem o qual se tornará praticamente impossível a prevenção e a repressão aos crimes contra o meio ambiente, voltando-se assim para uma eficiente fiscalização ambiental pelos órgãos públicos.

Existe no Brasil um verdadeiro arsenal legislativo abarcando o direito ambiental, a saber: leis, decretos, resoluções e portarias. Assim é natural que, mesmo na posse de ampla legislação, em razão do caráter multidisciplinar do direito ambiental, o operador do direito ao caso concreto tenha dificuldade e promover a necessária efetividade das referidas normas quiçá sua fiscalização exitosa.

Para a resolução desses conflitos, bem como para suprir eventual ausência de normas, pode o aplicador do direito amparar-se nos princípios jurídicos da Constituição Federal e das legislações infraconstitucionais.

Nesta ótica Marcia Leuzinger Dieguez e Sandra Cureau afirmam que:

Para que uma disciplina seja considerada autônoma, é necessária a identificação de princípios e normas que lhe sejam próprios. O Direito Ambiental, cuja autonomia apenas foi reconhecida em meados de 1990, teve inicialmente, reconhecidos os princípios do poluidor pagador e da prevenção, seguindo-se da identificação de outros, como o do usuário pagador, da cooperação, da participação, da informação e mais recentemente da precaução $(2008$, p.13).

Nesta seara evolutiva dos pilares principiológicos do direito ambiental, tratar-se-á na presente pesquisa que o Princípio do Desenvolvimento Sustentável trouxe a tona o ser humano como centro dos interesses ambientais, sendo ele, a um só tempo, sujeito ativo e passivo da desordem ambiental na prática de crimes ambientais.

Assim seus postulados tratam da desorganização estatal, por conta do liberalismo econômico, verdadeiro fantasma da injustiça social em que o intervencionismo estatal prepondera em favor de interesses globais econômicos, esquecendo-se do individualismo.

$\mathrm{Na}$ últimadécada do século $\mathrm{XX}$, osdiscursos e práticas favoráveisao desenvolvimentosustentável ganharamforça no Brasil e passaram aser constantemente considerados na formulação das políticaspúblicas,bem como na criaçãodenossos instrumentos legais voltados à defesado MeioAmbiente, com ênfase no cenário local.

Atualmente a concepção de Desenvolvimento Local e Sustentável, trazida por JESUS (2006, p.25-26), segundo o qual,o desenvolvimento local sustentável trata-se de um processo que envolve e motiva pessoas e instituições, a buscarem uma "transformaçãoda economia e da 
sociedade locais", gerando oportunidades sustentáveis, transpassando dificuldades e favorecendo a melhoriadas condições de vida e/ou da qualidade de vida da população local.

Visando estabelecer a relevância do tema e a necessidade da criação de Delegacias Especializadas no combate aos crimes ambientais será abordada a questão do poder de polícia, trazendo sua conceituação, diferenciação entre PolíciaAdministrativae PolíciaJudiciária, as características específicas desses poderes, seus limites e embasamento legal para o exercícioda políciaambiental, bem como a questão da responsabilização penal por dano ambientalexercido pela Polícia Judiciária, com enfoque no Estado de São Paulo.

\section{POLÍTICAS PÚBLICAS}

As políticas públicas voltadas para o desenvolvimento sustentável, como bem afirma CAVALCANTI (2002, p.25), "não podem desprezar as relações entre o homem e a natureza que ditam o que é possível em face do que é desejável”. Buscando aquilo que BRAUN (2001, p.12) denomina "ponto de equilíbrio entre os trêscomponentes do meio ambiente: o natural/ecológico, o social e o econômico".

No entanto, para que essa relação harmoniosa e essa mudançaparadigmática a favor da sustentabilidade se tornem efetivamente possíveis eexequíveis, é preciso que a sociedade tenha a "noção de que não há uma soluçãoglobal sem uma ação local". Logo, "é necessário que as comunidades cuidem doseu próprio ecossistema", conforme assevera DE SOUZA (in PHILLIP JR, et al, 2002,p.294).

Logo essas ações locais de defesa do meio ambiente e promoção dodesenvolvimento local sustentável precisam do apoio do Poder Público, em todas assuas instâncias, uma vez que para SPADOTTO E ELIAS (2011) a "política pública podeser compreendida como o conjunto de ações desencadeadas pelo Estado, nasescalas: federal, estadual e municipal, com vistas ao bem comum".

Esse entendimento denota a importância da integração dessas políticas e aconsequente necessidade de atuação conjunta entre os órgãos responsáveis porsua execução e condução, principalmente no que se refere à fiscalização ambiental e ações de combate.

Entretanto, a operacionalização das políticas públicas dispõe de algunsinstrumentos, os quais, segundo BRAGA (2005, p.89-90) podem ser agrupados nosseguintes grupos: de ordenamento territorial, de tomada dedecisão, dentre estes instrumentos consta a fiscalização 
ambiental enfatizada nesteestudo, e que configura:um instrumento corretivo e de gestão ambiental. Pode se dar em caráterpreventivo e coercitivo, a depender do momento e das circunstâncias em que ocorra.

Preventivamente ela ocorre em decorrência de visitas sistemáticas às áreasidentificadas como prioritárias ou estratégicas pelo órgão ambiental, o quegarante um maior controle. Ao mesmo tempo, as visitas podem serassistemáticas, valendo-se do caráter surpresa para obtenção do flagrantede ato ilícito pela polícia ambiental (BRAGA, 2005, p.106).

Fica, então, evidente que o ato de fiscalizar possui duas intenções: apreventiva (e por que não dizer de caráter educativo), por meio de incursõesregulares dos agentes fiscalizadores até o local onde haja o risco de algum tipo dedano ambiental, buscando evitar a sua ocorrência; e a coercitiva (ou repressiva) queconsiste na autuação, seguida da devida responsabilização daqueles que possamvir a cometer crimes ambientais, podendo tratar-se de pessoas físicas ou jurídicasde acordo com a legislação em vigor.

A população tem o direito de obter determinados serviços por intermédio do Governo, cabendo a este assegurar determinados direitos aos cidadãos, notadamente os direitos fundamentais sociais como saúde, educação, segurança pública. O Poder Executivo não apenas executa as leis, mas determina suas políticas e programas necessários à realização dos ordenamentos legais.

Nas políticas públicas, o próprio planejamento estatal tem por finalidade o atingimento do interesse público, assim não se trata de eleição pura e simples de prioridades governamentais e, sim, a concretização da opção já levada a efeito pelo legislador que, ao elaborar tais metas em planos de ação executiva, deve junto com o administrador.

No que tange ao Direito Ambiental, é forçoso reconhecer-se a existência de suficiente legislação ordinária e capítulo constitucional para a proteção do ambiente e salvaguarda da sadia qualidade de vida. Todavia, é deficiente sua implementação, uma vez que os órgãos estatais estão insuficientemente equipados para sua implementação, ou diante das dificuldades da realidade político-administrativa ou de interesses econômicos de grupos poderosos tornamse tolerantes/displicentes/condescendentes. 
Assim, no âmbito do Estado de São Paulo, através da implementação do Decreto n. ${ }^{\circ}$ 59.374, de 22 de julho de $2013^{3}$ publicado assinado pelo governador do Estado de São Paulo Geraldo Alckmin alterou o nome da Divisão de Investigações sobre Infrações contra o Meio Ambiente, do Departamento de Polícia e Proteção à Cidadania (DPPC), que passou a ser chamada de Divisão de Investigações sobre Infrações de Maus Tratos a Animais e demais Infrações do Meio Ambiente.

A mudança visou dar maior ênfase para o combate e às investigações de maus tratos e qualquer tipo de crueldade contra os animais - tarefas já desempenhadas e inseridas nas infrações do meio ambiente, objetivando assim através desta mudança a efetiva implementação, pelos órgãos estatais da efetividade a questão ambiental.

\section{FISCALIZAÇÃO AMBIENTAL}

O Estado deve agir através de seus órgãos ambientais de forma eficaz atuando em defesa do meio ambiente para evitar sua degradação, utilizando de todos os instrumentos à sua disposição e usar do poder/dever de polícia ambiental.

Na seara ambiental, o agir administrativo está permeado de deveres de conservação do ambiente natural, impostos pela ordem constitucional vigente e também pela legislação infraconstitucional recepcionada (como é o caso da Lei da Política Nacional do Meio Ambiente, Lei Federal no. 6.938/81 ${ }^{4}$ ) e editada em conformidade com a Constituição de 1988. Essas previsões constitucionais e ordinárias têm comando coercitivo condizente com a garantia de sua observância pelo governante e possibilita o controle de seus atos.

\footnotetext{
${ }^{3}$ DECRETO N ${ }^{\circ}$ 59.374, DE 22 DE JULHO DE 2013 -Altera a denominação da Divisão de Investigações sobre Infrações contra o Meio Ambiente, do Departamento de Polícia de Proteção à Cidadania - DPPC, da Polícia Civil do Estado de São Paulo, e dá providências correlatas. GERALDO ALCKMIN, Governador do Estado de São Paulo, no uso de suas atribuições legais, Decreta: Artigo $1^{\circ}$ - A Divisão de Investigações sobre Infrações contra o Meio Ambiente, do Departamento de Polícia de Proteção à Cidadania - DPPC, da Polícia Civil do Estado de São Paulo, da Secretaria da Segurança Pública, passa a denominar-se Divisão de Investigações sobre Infrações de Maus Tratos a Animais e demais Infrações contra o Meio Ambiente. Artigo $2^{\circ}$ - O inciso IV do artigo $3^{\circ}$ do Decreto $n^{\circ} 54.359$, de 20 de maio de 2009, passa a vigorar com a seguinte redação: "IV - Divisão de Investigações sobre Infrações de Maus Tratos a Animais e demais Infrações contra o Meio Ambiente, com: a) Assistência Policial; b) $1^{\mathrm{a}}$ Delegacia de Polícia; c) $2^{\mathrm{a}}$ Delegacia de Polícia;". (NR) Artigo $3^{\circ}$ - Este decreto entra em vigor na data de sua publicação, ficando revogada a alínea "b", do inciso I, do artigo $7^{\circ}$, do Decreto $\mathrm{n}^{\mathrm{o}}$ 57.546, de 28 de novembro de 2011. Palácio dos Bandeirantes, 22 de julho de 2013. Disponível em:http://www.al.sp.gov.br/repositorio/legislacao/decreto/2013/decreto-59374-22.07.2013.html. Acesso em 09.06.2016.

${ }^{4}$ Disponível em http://www.planalto.gov.br/ccivil_03/leis/L6938.htm. Acesso em 01.06.2016
} 
Em que pese ocorrer o cumprimento espontâneo das normas no meio social, não se pode duvidar da possibilidade de sua inobservância, surgindo a necessidade da coercibilidade disposta nas regras jurídicas de direito objetivo.

A formulação de políticas públicas relativas ao meio ambiente compete ao Poder Legislativo que, em síntese, representa a vontade do povo, formulando as diretrizes a serem seguidas. Por sua vez, compete ao Poder Executivo a sua execução e a implementação. Assim, não compete ao poder Judiciário a formulação de políticas públicas ambientais.

Um dos aspectos mais importantes da participação da sociedade na proteção do meio ambiente é o controle da Administração Pública, por intermédio do Poder Judiciário exercido diretamente, quando o cidadão ingressa com a Ação Popular ou através do Ministério Público, o qual representa institucionalmente os interesses da sociedade, quando constatada a ineficiente implementação de políticas públicas para garantir a higidez ambiental e a saúde da população, socorrendo-se, nesta hipótese, ao Poder Judiciário para garantir o exercício efetivo desse direito.

No Estado de São Paulo após a publicação do Decreto Estadual nº 60.342, de 04-04$2014^{5}$, que instituiu novas regras para a apuração de infrações ambientais e imposição de penalidades administrativas, iniciou-se uma nova fase de programas de Fiscalização.

O Guia de Procedimentos Administrativos de Fiscalização - GPAF realizado pela Secretaria do Meio Ambiente e Coordenadoria de Fiscalização Ambiental é um marco dentre tantos outros importantíssimos para a fiscalização ambiental do Estado, como a implantação dos Programas de Fiscalização Integrada (Operação Corta-Fogo, MAIS -Monitoramento Ambiental por Imagens de Satélite, SIM-Plano Integrado de Fiscalização em Unidades de Conservação, SIMMar - Fiscalização Marítima Integrada, entre outros), a implantação do Programa Estadual de Conciliação Ambiental e do Módulo de Fiscalização Eletrônico.

Esta nova face da fiscalização ambiental tão somente tornou - se possível e m razão da efetiva integração dos órgãos do Sistema Ambiental Paulista, que foi de fundamental importância na elaboração, discussão e execução dos planos. Integração esta que se revelacomo um dos novos paradigmas da fiscalização.

\footnotetext{
5isponível em http://www.al.sp.gov.br/repositorio/legislacao/decreto/2014/decreto-60342-04.04.2014.html. Acesso em 06.06.2016

${ }^{6}$ Disponível em http://www.ambiente.sp.gov.br/cfa/files/2015/01/GPAF-guia-proced-adm-fisc-dez-2014.pdf. Acesso em 06.06.2016.
} 


\section{PODER DE POLÍCIA ADMINISTRATIVO}

A Lei Federal $n^{\circ}$ 9.605/98define em seu artigo 70, a infração administrativa ambiental como sendo toda ação ou omissão que viole as regras jurídicas de uso, gozo, proteção e recuperação do meio ambiente. O processo administrativo é o caminho pelo qual a administração pública exige do particulardeterminada obrigação, seja de fazer, não fazer ou cessar, e até mesmo a exigência de uma prestaçãopecuniária.

Entretanto, cabe aqui ressaltar que, da mesma forma, aAdministração Públicaencontrasesujeita aos mandamentos legais, sob pena de praticar, dentro de suas atividades funcionais, atos inválidos, se expondo à apuração da responsabilidade disciplinar, criminal ou civil, de acordo com o caso. Além disso, a desobediência aos requisitos legais quanto à forma do ato induz a inexistência domesmo, viciando-o substancialmente e tornando-o, portanto, passível de invalidação.

Chama-se Poder de Polícia administrativa a faculdade conferida pela lei à Administração Pública para conciliar o uso de direitos e liberdades individuais ao interessepúblico, entretanto a lei também limita este poder a fim de coibir abusos.

Ou seja, tal poder é uma prerrogativa da Administração Pública, que legitima a intervenção na esfera jurídica do particular em defesa de interesses maiores relevantes para a coletividade, desde quefundado em lei anterior que o discipline e defina seus contornos, e é dotado dos atributos da discricionariedade, da auto-executoriedade e da coercibilidade, inerentes aos atos administrativos.

Investida do poder de polícia, a Polícia Militar Ambiental do Estado de São Paulo ${ }^{7}$ desenvolve suas atividades de segurança pública voltadas às ações pertinentes ao meio ambiente.

O poder de polícia ambiental é o principal instrumento de controle social para garantir ao coletivo, o meio ambiente ecologicamente equilibrado previsto na Carta Magna. É o deverpoder exercido pela administração pública operando restrições na esfera privada com o

${ }^{7}$ Disponível em: http://www3.policiamilitar.sp.gov.br/unidades/cpamb/. Acesso em 09.06.2016 
objetivo de zelar pelo bem estar da sociedade. As sanções administrativas, impostas por esse poder, devem ser aplicadas com observância dos princípios da proporcionalidade e a legalidade, bem como, o do devido processo legal de modo a permitir ao administrado o direito à ampla defesa e ao contraditório.

Trata-se de um poder eficaz que, na medida de suas atribuições e de sua capacidade auto executora, tem ajudado o Estado brasileiro a inibir e combater condutas de potencial lesivo ao meio ambiente e fazendo impor o interesse coletivo sobre o individual.

\section{SANÇÕES ADMINISTRATIVAS PARA INFRAÇÕES AMBIENTAIS}

Nos termos do artigo 72 da Lei Federal $n^{\circ} 9.605 / 98^{8}$ eartigo $3^{\circ}$ do Decreto Federal $n^{\circ}$ $6.514 / 08^{9}$, norma esta regulamentadora da citada lei, as infrações administrativas são punidas com as seguintes sanções:

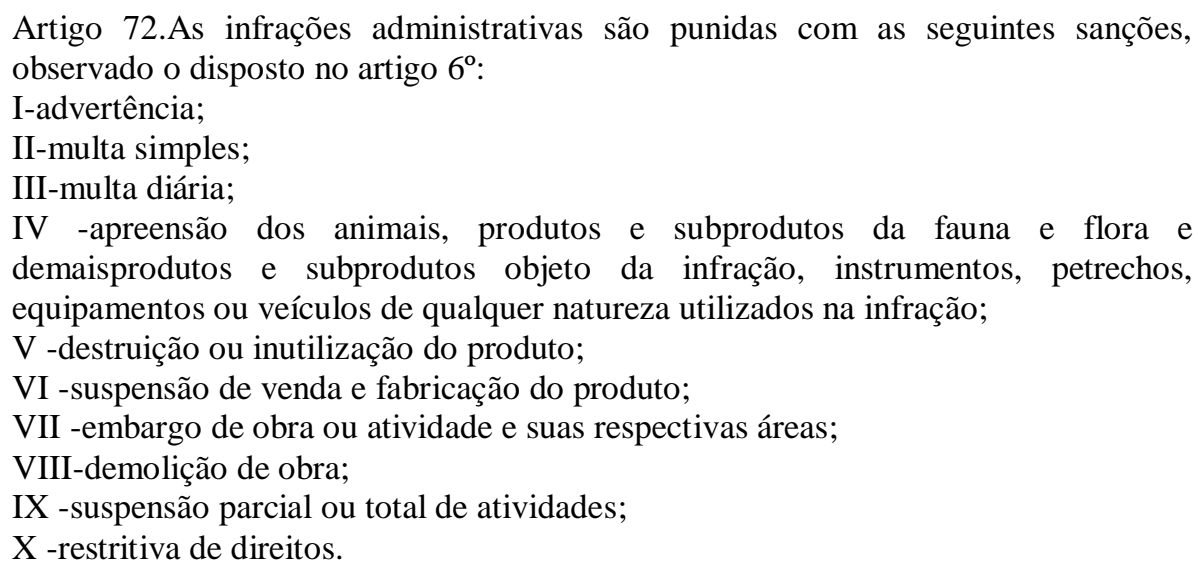

As sanções descritas nos item I, II ou III não excluem a possibilidade de aplicação concomitantemente com as demais.Desta forma, a partir da constatação do dano ambiental pelos órgãos de fiscalização, com a respectiva lavratura do Boletim de Ocorrência Ambiental, já se inicia o processo de apuração das responsabilidades administrativas, vez que o Estado pratica a proteção do meio ambiente através de seus órgãos administrativos, com vistas a efetivar a responsabilização nesta esfera através da lavratura do Auto de InfraçãoAmbiental.

Nesta seara, a constatação da infração pode dar ensejo à tomada de medidas administrativasprévias como a apreensão de bens e animais.

\footnotetext{
${ }^{8}$ Disponível em: http://www.planalto.gov.br/ccivil 03/leis/L9605.htm. Acesso me 06.06.2016

9 Disponível em: www.planalto.gov.br/ccivil_03/decreto/D3179.htm. Acesso em 06.06.2016.
} 
As ações de controle e fiscalização que visam a prevenção e repressão das infrações cometidas contra a flora e fauna no Estado de São Paulo, são de responsabilidade da Coordenadoria de Fiscalização Ambiental da Secretaria de Estado do Meio Ambiente (SMA/CFA), mais especificamente no Departamento de Fiscalização (DF)e nos Núcleos de Fiscalizaçãoe Gestão deAutos de Infração Ambientaldos Centros Técnicos Regionais de Fiscalização (CTRF/NFGAIA),que agem em conjunto com o Comando de Policiamento Ambiental da Policia Militar do Estado de São Paulo.

Desta forma, a PolíciaMilitarAmbiental lavra o Auto de Infração Ambiental (AIA), em decorrência deTermo de Cooperação entre as Secretarias de Estado do Meio Ambiente e da Segurança Pública.

OAuto de Infração Ambiental (AIA)é o documento que inaugura o processo administrativo destinado à apuração da existência, ou não, da infração ambiental e que impõe, de forma expressa, penalidade ao infrator.

Deve, necessariamente, ser formal e preencher requisitos previstos na norma ambiental aplicável. É oriundo do poder de polícia que detém a administração pública e, por ser da espécie de atosadministrativos punitivos, são vinculados à lei e devem respeitar, integralmente, o princípio da legalidade.

O Auto de InfraçãoAmbientalpode ser imputado à pessoa física ou jurídica, de direito público ou privado, que tenha concorrido, por ação ou omissão, para a prática da infração.

\section{POLÍCIA ADMINISTRATIVA X POLÍCIA JUDICIÁRIA}

Uma importante distinção precisa ser feita, no que diz respeito aos propósitos concernentes à polícia administrativa e à polícia judiciária, da qual as Delegacia de Polícia de Combate aos Crimes Ambientais fazem parte.

Segundo MEIRELLES (2009) a Polícia Judiciária compreende determinados órgãos (Polícias Civis) ao passo que a Polícia Administrativa é ligada estruturalmente à Administração Pública e difundida por todas as suas esferas (União, Estados e Municípios).

A Polícia Administrativa, de acordo com BARROS (2008, p.235), “incide sobre direitos, bens ou atividades, impedindo através de ordens, proibições e apreensões o exercício antissocial dos direitos individuais". 
Já a Polícia Judiciária, consoante a ótica desse mesmo autor, tem como finalidade a apuração de infrações penais por meio da instauração de procedimentos policiais (inquéritos e termos circunstanciados de ocorrência) para posterior encaminhamento à Justiça (atribuições próprias das polícias civis).

Desta forma, a polícia preventiva é classificada como "polícia administrativa" e a polícia repressiva como "polícia judiciária".

Em linha de pensamento similar esclarece sobre as diferenças entre polícia administrativa e judiciária MOREIRA NETO (2001, p.328-329):

\begin{abstract}
“O Estado atua na prevenção (precedendo o rompimento da ordem pública) e na repressão (sucedendo o rompimento da ordem pública) desempenhando funções de polícia de ordem pública. Também atua no desempenho da função de polícia judiciária, quando da preparação da repressão penal.Daí decorrem as duas modalidades de polícia que atuam na segurança pública: a polícia administrativa de ordem pública e a polícia judiciária, cada uma delas desempenhando funções distintas e definidas, embora possam estar cumuladas na mesma instituição, tudo dependendo dos critérios do legislador".
\end{abstract}

Para dirimir, de forma simples e objetiva, possíveis dúvidas em relação às atribuições próprias dessas duas polícias, esclareça-se que quando ocorrer um crime (aqui entendido como todo fato típico e antijurídico) contravenção penal ou ato infracional haverá a ação direta da polícia judiciária, valendo-sedo seu Poder de Polícia, procedendo com a investigação que levará à responsabilização criminal dos infratores.

\title{
6 MINISTÉRIO PÚBLICOESTADUAL
}

Umadas mais importantes instituições que combatem os crimes ambientais é o Ministério Público, por meio de seus representantes(procuradores e promotores de justiça), pois, dentre suas atribuições, elencadas na Constituição ${ }^{10}$, constam a promoção de inquérito e ação civil para proteger o meio ambiente, a requisição deinstauração de inquéritos policiais (esfera criminal), para a autoridade policial (delegados de polícia) e o controle externo da própria atividade policial.

\footnotetext{
${ }^{10}$ Art. 129. São funções institucionais do Ministério Público: (...) III - promover o inquérito civil e a ação civil pública, para a proteção do patrimônio público e social, do meio ambiente e de outros interesses difusos e coletivos;
} 
Especialmente no que tange ao inquérito civil, instrumento indispensável para a responsabilização do causador de dano ambiental, o promotor de justiça é responsável por sua instauração, para apurar os todos os fatos considerados lesivos ao meio ambiente (na esfera civil) e por providenciar a promoção da ação civil pública.

Já no que se refere especificamente à responsabilização criminal, relativa à apuração de infrações penais lesivas ao meio ambiente (crimes ambientais) cabe à autoridade policial, delegado de polícia, competente que atue na área de ocorrência do fato investigá-lo, por meio da instauração de procedimento específico (inquérito policial ou termo circunstanciado de ocorrência) e remetê-lo, após sua conclusão, ao Representante do Ministério Público, a quem caberá oferecer denúncia para o posterior julgamento do processo pela autoridade judiciária, respeitando-se todos os seus direitos e garantias individuais dos imputados previstos no artigo $5^{\circ}$ e incisos da Constituição Federal, dentre os quais os princípios do contraditório e da ampla defesa.

Vale relembrar que as pessoas (físicas ou jurídicas) que lesarem o meio ambiente estarão sujeitas a serem responsabilizadasadministrativa, civil e penalmente, conforme consta no artigo 225, § $3^{\circ}$, da Carta Magna desta República ${ }^{11}$.

O Ato Normativo $n^{\circ}$ 552/08 da Procuradoria Geral de Justiça de São Paulo de 4 de setembro de $2008^{12}$, instituiu o Grupo de Atuação Especial de Defesa do Meio Ambiente (GAEMA) e a Rede de Atuação Protetiva do Meio Ambiente, no âmbito do Ministério Público do Estado de São Paulo. Assim, constitui missão a ser atendida pelo GAEMA e pela Rede de Atuação Protetiva do meio Ambiente a identificação, prevenção e repressão das atividades causadoras de degradação ambiental no Estado de São Paulo.

A atuação do GAEMA será realizada prioritariamente na fase de investigação, tomada de compromisso de ajustamento de conduta, arquivamento ou promoção da ação civil cabente, cumprindo ao Promotor de Justiça Natural oficiar nos autos do processo judicial até final decisão.

O Grupo de Atuação Especial de Defesa do Meio Ambiente competirá, dentre outras, as seguintes atribuições: a) oficiar nas representações, inquéritos civis, procedimentos preparatórios de inquéritos civis para a defesa e proteção dos bens ambientais nos temas eleitos como prioritários, mediante atuação integrada com o Promotor de Justiça Natural; b)

\footnotetext{
${ }_{11}^{11}$ Disponível em http://www.planalto.gov.br/ccivil_03/Constituicao/Constituicao.htm. Acesso em 01.06.2016

${ }^{12}$ Disponível em http://www.mpsp.mp.br/portal/page/portal/cao_urbanismo_e_meio_ambiente/rede_gaema
} 
tomar compromissos de ajustamento de conduta nos procedimentos de sua alçada; c) promover as medidas judiciais cabentes e necessárias à defesa e proteção dos bens ambientais nos temas eleitos como prioritários; d) promover a efetiva mobilização das Promotorias de Justiça do Meio Ambiente integrantes do núcleo regionalizado para a consecução da atuação integrada em relação a todos os temas regionais.

\section{POLÍCIA MILITAR AMBIENTAL}

O Comando de Policiamento Ambiental do Estado de São Paulo é a unidade da Polícia Militar $^{13}$ especializada em meio ambiente, responsável pela aplicação da legislação ambiental do estado e órgão integrante do SISNAMA (Sistema Nacional do Meio Ambiente).

A Polícia Ambiental e suas Unidades Subordinadas constituem-se em uma instituição direcionada para a proteção do meio ambiente na América Latina e buscam demonstrar a transparência e o esforço permanente, daquilo que está sendo feito para a preservação.

O Comando de Policiamento Ambiental fiscaliza crimes ambientais, tais como: caça, pesca de animais silvestres e armamentos para este fim, retirada ilegal de madeira, palmito, supressão de mata atlântica, soltura de balões de fogo, entre outros ${ }^{14}$.

Em operações realizadas neste ano de 2016, a Polícia Militar Ambiental atendeu mais de 26 mil ocorrências, nas quais foram presas 157 pessoas em flagrante. As equipes ainda fiscalizaram quase 10 mil propriedades rurais, aplicaram mais de 6 mil autuações,

\footnotetext{
${ }^{13}$ Para denunciar atividades que põe em risco fauna e flora, é possível ligar no 190 da Polícia Militar ou por meio do Disque Ambiente - 0800113560. novembro de 2015 flagraram na parte externa de uma residência 02 gaiolas contendo 1 pássaro em cada uma, ambos pertencentes a fauna silvestre nativa brasileira. Os policiais entraram em contato com os moradores onde foram atendidos pela esposa do denunciado que não estava em casa, e informou que as aves estavam registradas, momento em que franqueou a entrada dos policiais para averiguação. Ao entrar na residência, os policiais localizaram mais 21 aves silvestres nativas, porém, 12 estavam sem anilhas. Ao fiscalizarem também dentro da residência, localizaram dentro de um guarda roupa 1 espingarda calibre 24, 01 espingardas de fabricação caseira, 96 cartuchos de vários calibres, estando alguns deflagrados, 08 frascos com pólvora, 132 espoletas, 02 apitos de madeira. Durante a fiscalização o responsável compareceu no local, e apresentou aos policiais um Cadastro Técnico Federal das aves com vencimento 31 julho de 2015, e não informou a procedência das demais aves. Diante dos fatos foi dada voz de prisão em flagrante delito pela posse ilegal de arma de fogo. O indiciado foi conduzido ao Distrito Policial da região, as aves foram apreendidas, e o indiciado ainda foi autuado em $\mathrm{R} \$ 6.000,00$ por ter em cativeiro 12 aves da fauna silvestre nativas sem autorização dos órgãos ambientais competentes. Um médico veterinário após perícia atestou que as aves foram capturadas recentemente e que poderiam serem novamente soltas na natureza. Disponível em http://www3.policiamilitar.sp.gov.br/unidades/cpamb/. Acesso em 09.06.2016.
} 
apreenderam 266 armas de fogo e vistoriaram mais de 4 mil embarcações e quase 23 mil veículos ${ }^{15}$.

O Comando de Policiamento Ambiental ${ }^{16}$ possui quatro batalhões, com sede em São Paulo, Birigui, Guarujá e São José do Rio Preto. "São 2.200 homens que exercem o patrulhamento ambiental, vocacionados para a defesa ambiental", enfatizou o Secretário Segurança Pública, Mágino Alves Barbosa Filho, no dia 05 de junho deste ano, na entrega de 18 novas viaturas ao Comando de Policiamento Ambiental (CPAmb) da Polícia Militar do Estado de São Paulo, que visa reforçar a frota.

\section{DELEGACIAS DE POLÍCIA ESPECIALIZADAS NO COMBATE AOS CRIMES AMBIENTAIS NO ESTADO DE SÃO PAULO}

O Decreto $\mathrm{n}^{\mathrm{o}} 54.359$, de 20 de maio de 2009 de São Paulo ${ }^{17}$ criou e organizou na Polícia Civil do Estado de São Paulo, da Secretaria da Segurança Pública, o Departamento de Polícia de Proteção à Cidadania - DPPC.

O Departamento de Polícia de Proteção à Cidadania - DPPC atua no âmbito do município de São Paulo e possui cinco Divisões de Investigações específicas, a saber: Divisão de Crimes contra o Consumidor; Divisão de Crimes contra a Saúde Pública; Divisão de Crimes contra o Meio Ambiente; Divisão de Crimes contra a Administração e Divisão de Crimes contra a Fazenda. Este Departamento tem como atribuição o exercício das atividades de polícia judiciária, administrativa e preventiva especializada, atuando com exclusividade no município da Capital no concernente ao registro e à apuração das infrações penais contra: o consumidor; a saúde pública, o meio ambiente, a Fazenda Pública Estadual e Municipal.

Em 22 de julho de 2013 oGovernador Geraldo Alckmin crioupor meio do Decreto ${ }^{\circ}$ 59.374 de 22 de julho de $2013^{18}$, a Delegacia Especializada na Investigação de Maus-tratos Contra Animaise demais Infrações contra o Meio Ambiente. Esta divisão criada é responsável

\footnotetext{
${ }_{16}^{15}$ Disponível em http://www.ssp.sp.gov.br/noticia/lenoticia.aspx?id=37465. Acesso em 09.06.2016

${ }^{16} \mathrm{O}$ Governo do Estado investiu R\$ 1,7 milhão na compra dos veículos, por meio da Secretaria do Meio Ambiente. O evento de distribuição das viaturas teve acompanhamento do secretário da Segurança Pública, Mágino Alves Barbosa Filho. Disponível em: http://www.ssp.sp.gov.br/noticia/lenoticia.aspx?id=37465. Acesso em 08.06.2016.

${ }^{17}$ Disponível emhttp://www.al.sp.gov.br/repositorio/legislacao/decreto/2013/decreto-59374-22.07.2013.html. Acesso em 08.06.2016.

${ }^{18}$ Disponível em: http://www.al.sp.gov.br/repositorio/legislacao/decreto/2013/decreto-59374-22.07.2013.html. Acesso em 08.06.2016.
} 
pela investigação de crimes de abusos, maus-tratos e demais atos de crueldade contra animais, além de outras infrações contra o meio ambiente cometidas no estado de São Paulo. A criação desta delegacia atende reivindicação de entidades ligadas à luta pela proteção dos animais e visa dar maior ênfase ao combate e às investigações de maus-tratos e qualquer tipo de crueldade contra os animais.

O órgão, que funcionava desde 2.009 como Divisão de Investigações sobre Infrações contra o Meio Ambiente, do Departamento de Polícia e Proteção à Cidadania (DPPC) ${ }^{19}$, conta com duas delegacias especializadas e uma assistência policial. A mudança evidencia o empenho da Polícia Civil para assegurar os direitos dos animais.

A mudança na nomenclatura busca evidenciar que crimes contra animais também são alvo de investigação da polícia. "A falta de uma palavra mencionando os animais junto ao nome da divisão policial sugeria a falsa ideia de que a proteção aos bichos não era exercida pela Polícia Civil de São Paulo”, declarou a Secretaria da Segurança Pública.

Na Capital, o Departamento de Polícia e Proteção à Cidadania (DPPC) abriga as duas delegacias, que integram a recém-renomeada Divisão de Investigações sobre Infrações e Maus Tratos a Animais e demais Infrações do Meio Ambiente.

Assim, pichar imóveis, jogar lixo em áreas públicas, soltar balões, maltratar animais e até "soltar fumaça", conforme a lei dos crimes ambientais (Lei 9605-98) são crimes ambientais combatidos pela Polícia Civil. Onze delegacias especializadas na Capital e na Grande São Paulo atuam exclusivamente na repressão a esses tipos de delitos.

Na Grande São Paulo, o combate aos crimes ambientais é feito por nove delegacias espalhadas pelas 39 cidades da região.

Segundo reportagem divulgada pela Secretaria de Segurança de São Paulo ${ }^{20}$ com o Delegado Dr. Pascoal Ditura,Titular da Delegacia Especializada na Seccional do Taboão da Serra, este afirmou que atua em sete cidades. Para isso, conta com uma equipe de dez investigadores e dois escrivães."É uma área de $1.165 \mathrm{~km}^{2}$, com muitas florestas e mananciais, sendo quase $80 \%$ Áreas de Proteção aos Mananciais (APM) e Áreas de Proteção Permanente (APP)". As ocorrências mais comuns são descarte de entulhos em áreas de preservação, corte de árvores e construções irregulares em mananciais.

\footnotetext{
${ }^{19}$ Endereço: Avenida São João n. ${ }^{\circ}$ 1247, Centro, São Paulo - Telefone: (11) 3338-0155.

${ }^{20}$ Disponível em: http://www.ssp.sp.gov.br/noticia/lenoticia.aspx?id=32770. Acesso em 08.06.2016
} 
No início deste ano, o Delegado comandou uma operação especial numa extensa área de mata nativa que contou até com o apoio do helicóptero Pelicano da Polícia Civil. Com a ajuda de equipamentos a bordo da aeronave, foi possível fotografar a placa de um caminhão que despejara entulho e se escondera no meio das folhagens. "Com isso, identificamos o motorista e o indiciamos em inquérito policial”, conta Ditura.

Ainda segundo informações da Secretaria de Segurança Pública de São Paulo ${ }^{21}$, obtidas em entrevista com o Delegado Titular da Delegacia de Investigações sobre Infrações contra o Meio Ambiente de Carapicuíba, Dr. José Damasceno Jr., este afirmou que sua jurisdição cobre oito municípios. São $851 \mathrm{~km}^{2}$ de Áreas de Preservação Ambiental, ricas em florestas e mananciais. A poluição do solo e rios, aterros clandestinos e captura de animais silvestres também são comuns na jurisdição de Damasceno "Desmatamento é o que mais tem", lamenta.

Na cidade de Osasco, o Delegado Titular da Delegacia sobre crimes contra o Meio Ambiente, Dr. José Roberto Pedroso, trava uma luta permanente contra o despejo de entulhos e a poluição ambiental - de fumaça expelida por fábricas a pichação de prédios, esta última, infração típica dos centros urbanos. "Jogar lixo no chão é crime ambiental”, ressalta.Outra incumbência das Delegacias de meio ambiente, explica Pedroso, é a fiscalização dos chamados "produtos controlados", que são tóxicos. Isso inclui até cloro vendido em supermercados. "A Polícia Civil apura o delito pelo inquérito policial e a Polícia Militar lavra multas administrativas", explica Pedroso.

\section{MANUAL DE POLÍCIA JUDICIÁRIA AMBIENTAL}

A Academia de Polícia Civil Dr. Coriolano Nogueira Cobra de São Paulo (ACADEPOL) criou um manual sobre investigação de crimes contra o meio ambiente. Lançado em 25 de março de 2.014, o "Manual de Polícia Judiciária Ambiental” foi idealizado para capacitar policiais civis, especialmente delegados, na apuração deste ramo de crimes e aumentar o combate nesta área.

"Precisávamos desenvolver uma doutrina de polícia judiciária neste tema", comentou o Diretor da Acadepol, Mário Leite de Barros Filho, na época do lançamento e publicação. A

${ }^{21}$ Disponível em: http://www.ssp.sp.gov.br/noticia/lenoticia.aspx?id=32770. Acesso em 08.06.2016 
obra apresenta uma legislação e jurisprudência concisas, com comentários sobre a lei ambiental, direito constitucional, administrativo, processual, penal e criminalística.

O manual fornece mecanismos jurídicos (meios de interpretação) que possibilitam a compreensão correta da Lei dos Crimes Ambientais (Lei Federal 9.605/98). "Antes de 1998, havia uma legislação dispersa, extensa e complexa relacionada a meio ambiente, que foi concentrada na Lei 9.605", explicou o diretor.

Mas havia ainda uma "lacuna doutrinária", que foi preenchida com a publicação do manual. Segundo Mário Leite, foi justamente a falta de uma doutrina que motivou o Núcleo de Estudos sobre o Meio Ambiente e Polícia Judiciária (NEMA), da Acadepol, a idealizar o manual. A própria gráfica da Acadepol fez a impressão de 2 mil exemplares.

O Núcleo de Estudos sobre o Meio Ambiente e Polícia Judiciária- NEMA integrado em sua maioria por delegados se reúne a cada um ou dois meses na Acadepol para estudar e debater as leis que tipificam os delitos ambientais, em especial a 9.605/98.

As conclusões de seus estudos contribuem para a elaboração da disciplina de meio ambiente, que consta na grade regular dos cursos de formação dos policiais civis. O NEMA também promove seminários com a participação de autoridades judiciais, policiais e especialistas na questão ambiental.

\section{CONCLUSÃO}

Diante da pesquisa trazida a discussão, verifica-se que o maior benefício que se tem com a especialização das Delegacias de Polícia é tornar o direito ambiental prioritário no trabalho de Polícia Judiciária, tanto de forma preventiva pela Polícia Militar Ambiental, quanto de forma repressiva pela Polícia Civil, através de investigações aprimoradas e com eficiência de resultados.

Há de se registrar que a especialização das Delegacias de Políciae sua implementação é opção institucional do Poder Executivo, que através das políticas públicas adequadas criam um espaço privilegiado dentro da organização da polícia judiciária, visando debater e enfrentar as questões ambientais.

Mais do que apenas facilitar a condução de inquéritos e Termos Circunstanciados, a especialização das unidades policiais chama a atenção do Delegado de Polícia para as tensões 
e peculiaridades da questão ambiental (por exemplo, presente versus futuro, desenvolvimento versus preservação).

A especialização também evidencia e destaca os órgãos públicos voltados para as questões ambientais, permitindo à sociedade uma cobrança mais direta quanto ao trabalho da Polícia Civil.

Há de se pontuar que o Poder Judiciário, no que tange a condenação justa dos autores de crimes ambientais, depende da iniciativa de outros agentes sociais e públicos, ainda que a tutela ambiental envolva direitos difusos e coletivos. Para isso, o Poder Judiciário necessita de da intervenção das polícias ambientais, dos órgãos de proteção ao meio ambiente com seu poder de polícia ambiental, do Ministério Público, dentre outras.Para isso também a sociedade pode colaborar, seja o cidadão individualmente pela ação popular, sejam as associações coletivamente pela ação civil pública.

Porém, faz-se mister esclarecer que esses outros agentes públicos ou sociais nem sempre conseguem dar conta da adequada proteção ambiental. De um lado, a esfera pública muitas vezes se mostra ineficiente na fiscalização e repressão ambiental. As estruturas burocráticas engessam os servidores; a falta de recursos impede uma fiscalização mais efetiva; o descompasso entre áreas técnicas e esferas políticas causa atritos que impedem uma atuação proveitosa do órgão; a fiscalização ambiental acaba sendo eventual ou acidental.

Enfim, falta um real comprometimento do poder público com a causa ambiental. De outro lado, com raras e honrosas exceções, os cidadãos dão mostras de cansaço e descrédito. São poucos os que continuam teimando e lutando para que as coisas mudem e o planeta seja salvo muitas vezes através de organizações não governamentais, e sem qualquer incentivo governamental. O ativismo ambiental exige do cidadão uma doação de seu tempo e de sua vida, muitas vezes sem um retorno imediato. É um trabalho muito mais de resistência e sobrevivência.

A instalação de Delegacias Especializadas no combate a crime ambientais é um importante passo em defesa do meio ambiente, mas somente produzirá efeitos se houver um real comprometimento da coletividade e do poder público para com a causa ambiental. 


\section{REFERÊNCIAS}

BRASIL. Constituição da República Federativa do Brasil de 1988. Disponível emhttp://www.planalto.gov.br/ccivil_03/Constituicao/Constituicao.htm. Acesso em 06.06.2016.

BRASIL. Decreto $n^{\circ} 59.374$, de 22 de junho de 2013. Altera a denominação da Divisão de Investigações sobre Infrações contra o Meio Ambiente, do Departamento de Polícia de Proteção à Cidadania - DPPC, da Polícia Civil do Estado de São Paulo, e dá providências correlatas.

Disponível:http://www.al.sp.gov.br/repositorio/legislacao/decreto/2013/decreto-5937422.07.2013.html. Acesso em 09.06.2016.

BRASIL. Decreto Federal no 3.179, de 21 de setembro de 1999. Dispõe sobre a especificação das sanções aplicáveis às condutas e atividades lesivas ao meio ambiente, $\mathrm{e}$ dá outras providências. Disponível em www.planalto.gov.br/ccivil_03/decreto/D3179.htm.Acesso em 06.06.2016.

BRASIL. Decreto Federal $n^{\circ}$ 6.514, de 22 de junho de 2008.Dispõe sobre as infrações e sanções administrativas ao meio ambiente, estabelece o processo administrativo federal para apuração destas infrações, e dá outras providências. Disponível http://www.planalto.gov.br/ccivil_03/_ato2007-2010/2008/decreto/d6514.htm. Acesso em 06.06.2016.

BRASIL. Decreto Estadual no 60.342 , de 04-04-2014. Dispõe sobre o procedimento para imposição de penalidades, no âmbito do Sistema Estadual de Administração da Qualidade Ambiental, Proteção, Controle e Desenvolvimento do Meio Ambiente e Uso Adequado dos Recursos Naturais - SEAQUA, e dá outras providências. Disponível emhttp://www.al.sp.gov.br/repositorio/legislacao/decreto/2014/decreto-6034204.04.2014.html. Acesso em 06.06.2016. 
BRASIL. Lei 6.938, de 31 de agosto de 1981.Dispõe sobre a Política Nacional do Meio Ambiente, seus fins e mecanismos de formulação e aplicação, e dá outras providências.Disponível http://www.planalto.gov.br/ccivil_03/leis/L6938.htm. Acesso em 01.06.2016.

BRASIL. Lei 9.605, de 12 de fevereiro de 1998.Dispõe sobre as sanções penais e administrativas derivadas de condutas e atividades lesivas ao meio ambiente, e dá outras providências. Disponível: http://www.planalto.gov.br/ccivil_03/leis/L9605.htm. Acesso em 01.06.2016.

BARROS, Wellington Pacheco. Curso de Direito Ambiental. 2. ed. São Paulo: Atlas, 2008.

BRAGA, Ricardo Augusto Pessoa. (2005) Avaliação dos instrumentos de políticas públicas na conservação integrada de florestas e águas, um estudo de caso na Bacia do Corumbataí-SP. São Carlos, EESC/USP. Tese de Doutorado em Engenharia Hidráulica e Saneamento. Disponível em www.teses.usp.br/teses/disponiveis/18/18138/tde-24102008103711/.../BragaS.pdf. Acesso em 09.06.2016.

BRAUN, Ricardo. Desenvolvimento ao Ponto Sustentável: novos paradigmas ambientais. Petrópolis/RJ: Vozes, 2001.

CAVALCANTI, Clóvis (Org.). Meio Ambiente, desenvolvimento sustentável e políticas públicas. 4.ed. São Paulo: Cortez: Recife: Fundação Joaquim Nabuco, 2002.

CRUZ, Ana Paula Fernandes Nogueira da. A culpabilidade nos crimes ambientais. São Paulo: Editora Revista dos Tribunais, 2008.

DIEGUEZ, Marcia Leuzinger; CUREAU, Sandra. Direito ambiental. Rio de Janeiro; Elsevier, 2008.

FIORILLO, Celso Antônio Pacheco. Curso de Direito Ambiental Brasileiro. 7 ed. Revisada, Atualizada e Ampliada. São Paulo, 2006. 
JESUS, Paulo de. Sobre desenvolvimento local e sustentável: algumas considerações conceituais e suas implicações em projetos de pesquisa. In: ASSUNÇÃO, Luiz Márcio de Oliveira; MACIEL FILHO, Adalberto; PEDROSA, Ivo Vasconcelos (Org.). Gestão do desenvolvimento local sustentável. Recife: EDUPE, 2006.

MEIRELLES, Hely L. Direito Administrativo Brasileiro. 35a ed. São Paulo: Malheiros, 2009.

MELLO, Celso Antônio Bandeira de. Curso de Direito Administrativo. 26ª ed. São Paulo: Malheiros Editores, 2009.

MOREIRA NETO, Diogo de Figueiredo. Mutações do Direito Administrativo. 2. ed. Rio de Janeiro: Editora Renovar, 2001.

PHILIPPI JR, Arlindo et al (Org.) Meio ambiente, Direito e cidadania. São Paulo: Universidade de São Paulo. Faculdade de Saúde Pública, Faculdade de Direito, Faculdade de Arquitetura e Urbanismo, Núcleo de Informações em Saúde Ambiental. Signus, 2002.

SPADOTTO, Anselmo Jose; ELIAS, Natalia Domingues. Políticas públicas ambientais e responsabilidade da pessoa jurídica. Jus Navigandi, Teresina, ano 16, n. 2872, 13 maio 2011. Disponível em: <http://jus.uol.com.br/revista/texto/19097>. Acesso em: 02.06.2016. 